\title{
Adaptive Power Charge Using PID Controller on DC Load Application
}

\author{
Farid Dwi Murdianto $^{1, a}$, Indhana Sudiharto ${ }^{1, b}$, Irianto $^{1, c}$, Ayu Wulandari ${ }^{1, d}$ \\ ${ }^{1}$ Department of Electrical Engineering, Politeknik Elektronika Negeri Surabaya, J1. Raya ITS, \\ Keputih Sukolilo 60111, Indonesia \\ afarid@pens.ac.id, bindhana@pens.ac.id, cirianto@pens.ac.id, ${ }^{\mathrm{d}}$ ayu124@gmail.com
}

\begin{abstract}
Battery is a very important necessity as electrical energy storage for DC load type. However, as electric energy storage, the battery has a limit storage capacity. The battery must be recharged when the electrical energy stored in the battery has been exhausted to keep the DC load in operation. Unfortunately, batteries in different types of DC loads have different voltages and capacities. So for charging the battery also requires a different voltage while the existing battery charger is generally static specifically for one type of batteries. From this problem, the paper proposed an adaptive power charge system as a system that can adaptively charge electrical energy on batteries that have different voltages and capacities through one port. The converter used in this paper is the buck converter to lower the output voltage from the input voltage. The system uses tracking duty cycle to know the type of DC load. After knowing the type of dc load then the system determines the setting point voltage. To keep the output voltage stable, the system uses PID control. With this adaptive power charge, the charging process will be more efficient and multifunction because it can be used for various types of DC load. The system can provide an output voltage of 19 volts when connected to a laptop and provides an output voltage of 5 volts when connected to a mobile phone on settling time of $10 \mathrm{~ms}$.
\end{abstract}

\section{Keywords-Adaptive, Buck Converter, PID Controller}

\section{Introduction}

In this modern era, technology develops very rapidly. More and more electronic equipment is made to facilitate human life. Electronic equipment requires electrical energy to operate. In this case the battery becomes a very important necessity as electrical energy storage for DC load type. If the electronic equipment is used continuously, the electrical energy stored in the battery will gradually deplete and consequently the electronic equipment could not operate. The electronic equipment in operation, the battery must be recharged. Unfortunately batteries in different types of DC loads have different voltages and capacities. The difference in voltage and capacity of each battery makes the charging process require different voltages from each other while the existing battery charger is generally equipped with a special adapter. Commonly used battery chargers nowadays tend to be static at voltage and current values that have been adjusted to the voltage and battery capacity so that can not be used for charging other battery types. Departing from the matter, it takes an adaptive power charge system, a system that can adaptively charge electrical energy on batteries that have different voltages and capacity through one port on the output side. To do this, the system must be able to detect the connected load, select what type of load is connected, determine the setting point voltage according to the type of load connected, and maintain the set point voltage when charging process. In the adaptive power charge system used in this paper, a source of 24 volt dc bus is used. A buck type converter is used to reduce the output voltage from the source voltage to provide the right output voltage and according to load requirements. The load selection process uses a tracking duty cycle which will then be used to determine the setting point voltage. The charging process uses the constant voltage method with a PID control to keep the output voltage stable at the setting point value [1]-[3]. With this adaptive power charge, the charging system will be more efficient and multifunctional because it can be used for various types of dc loads. In this paper there are 2 types of dc load used, namely Mobile and Laptop, each of which has a battery with a different voltage and capacity. Mobile phones require a 5 volt charging voltage while a laptop requires a 19 volt charging voltage.

\section{Research Methodology}

This proposed system requires a converter that can be charge mobile phone and laptop only with single output. 


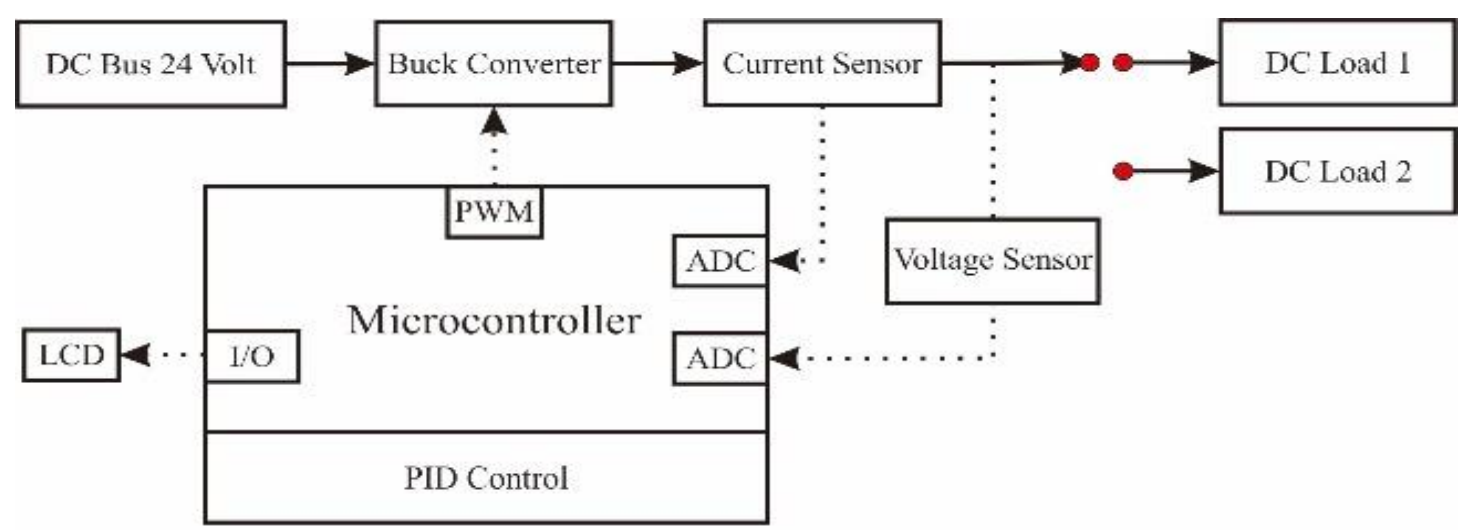

Note:

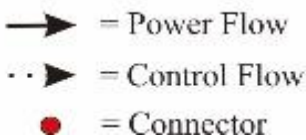

Figure 1. Overall System of Adaptive Power Charge

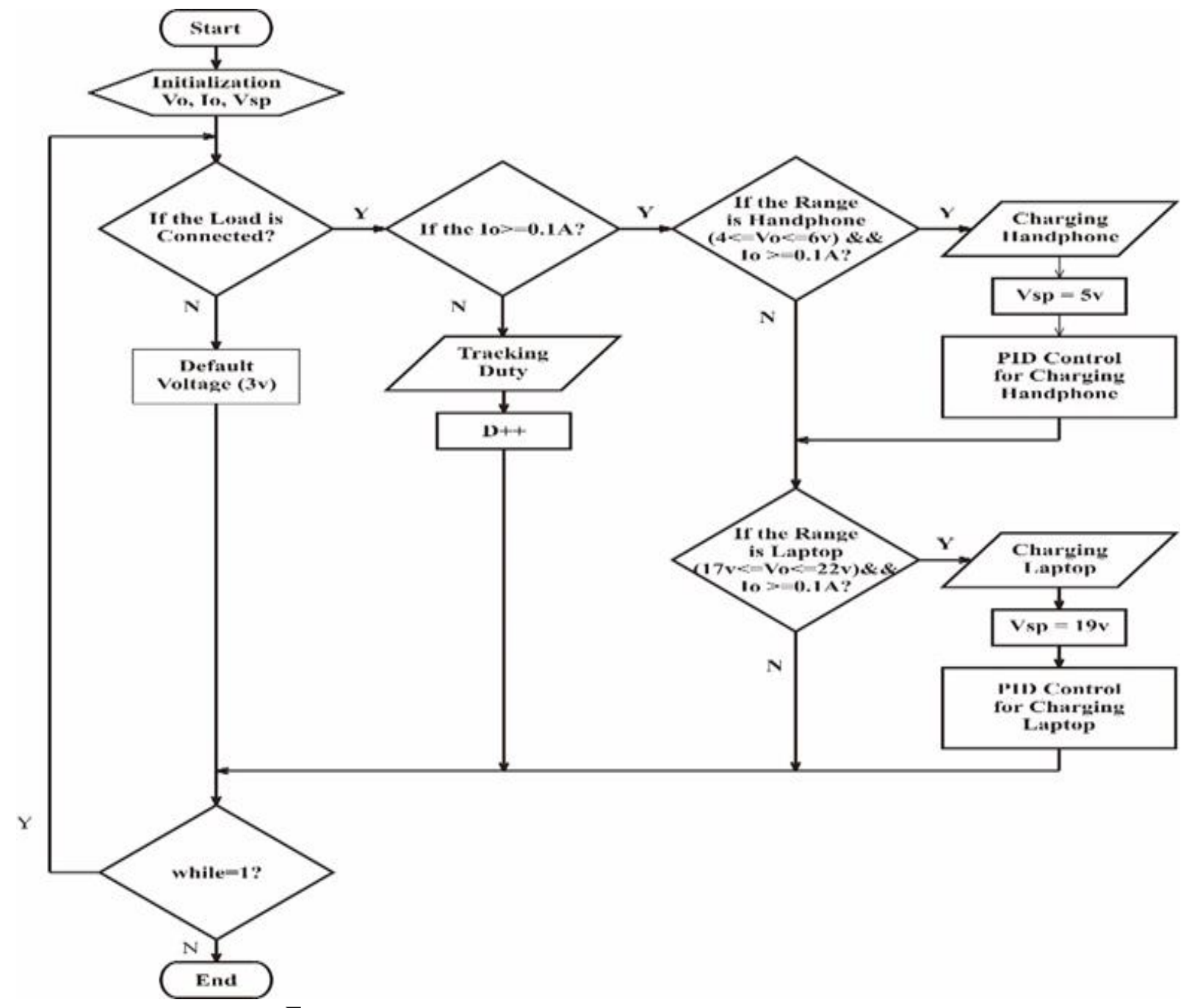

Figure 2. Flowchart Overall System of Adaptive Power Charge 
Figure 1 present a block diagram of adaptive power charge system with dc bus 24 volt as energy source. The energy from the dc bus is set from 0-24 volts using regulation of buck converter (step down DC-DC converter) as a charging supply of various DC Loads. If the system is connected with DC load, the system will recognize the type of DC load. Then the system will determine the setting point voltage that corresponds to the type of DC load. The current sensor and the voltage sensor will transmit data to the microcontroller. And then the microcontroller will give response to keep the output voltage stable at the set point value through PID control [4]-[6].The control is used in this research is the PI controller. This Research goal is to evaluate the performance PI Controller to manage dynamic energy from PV.

From the flowchart shown in Figure 2, it is explained that the first thing to do is determine the variable parameters needed. By initializing $V_{o}$ is the output voltage, Io is the output current, Vsp is the setting point voltage. If the load is not connected, the system will set a default voltage of 3 volts. If there is a load connected and the current is less than 0.1 ampere, the system will track the duty cycle. After reading the current (Io) $>=0.1 \mathrm{~A}$, the program will select what type of load is connected, whether Mobile or Laptop. If the voltage reads 4 volt $<V_{0}<5$ volt, the load connected is Mobile. Whereas if the voltage reads 17 volt $<$ Vo $<22$ volt, the load connected is Laptop. The system will determine the set point voltage (Vsp) based on the type of load connected. Vsp Mobile applied for 5 volts and Vsp Laptop applied for 19 volts. After determining the value of the next setting point it will be controlled by the PID control to keep the buck converter output voltage constant at the setting point value until the load is released [7]-[10].

\section{A. Design of Buck Converter}

Buck converter is electronic circuit used to convert dc voltage to dc voltage. Figure 3 present a circuit of buck converter. Design of adaptive power charge with buck converter circuit is need to know the biggest power of dc load that will be connected. In this research, Mobile and Laptop for dc load are used. Laptop need 65 watt power and Mobile need 10 watt power for charging. Therefore, to design a buck converter, it uses the maximum power calculation of the Laptop.

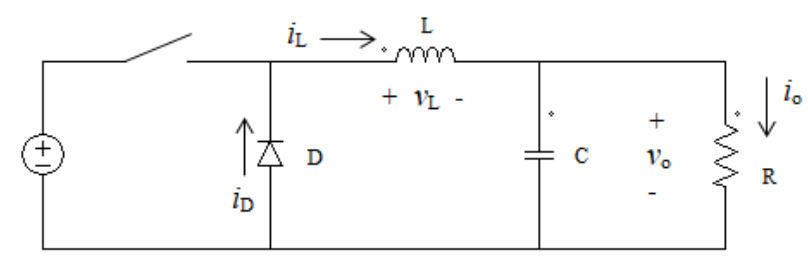

Figure 3. Buck Converter Circuit

Vo buck $=$ Vin $\times$ D

$\mathrm{L}=1 / \mathrm{f} \times(\mathrm{Vin}-\mathrm{Vo}) \times((\mathrm{Vo}+\mathrm{Vf}) /(\mathrm{Vin}+\mathrm{Vf})) \times 1 / \Delta \mathrm{iL}$

$\mathrm{C}=\Delta \mathrm{iL} / 8 \times \Delta \mathrm{Vo} \times \mathrm{f}$

Note:

Vin : Input voltage

Vo : Output voltage

L : Inductor

C : Capacitor

$\Delta \mathrm{iL}:$ Ripple current

$\Delta$ Vo: Ripple voltage

Equation (1) is applied for output voltage of buck converter design, (2) for inductor design, and (3) for capacitor design, all equations are required to design a buck converter. In this paper, buck converter used to control input voltage of adaptive power charger for dc load. Table 1 is present design value of buck converter.

Table 1. Design of Buck Converter

\begin{tabular}{|c|c|c|c|}
\hline Parameter & Symbol & Value & Unit \\
\hline Input voltage & Vin & 24 & Volt \\
\hline Output voltage & Vo & 19 & Volt \\
\hline Ripple current & $\Delta i L$ & $20 \%$ & Ampere \\
\hline Ripple voltage & $\Delta V o$ & $0.1 \%$ & Volt \\
\hline Frekuensi switching & fs & 40 & KHz \\
\hline Inductor & $\mathrm{L}$ & 114.8 & $\mathrm{uH}$ \\
\hline Capacitor & $\mathrm{C}$ & 112.5 & $\mathrm{uF}$ \\
\hline
\end{tabular}

The design value of buck converter above is used to get the output wave response using software simulation. 
The simulation results below explain that the buck converter is connected with a different load.

Figure 4 is simulation of buck converter connected to a Laptop that gives 19.03 volt charging voltage. Figure 5 is simulation of buck converter connected to a Mobile that gives a 4.22 volt charging voltage.

\section{B. Design of PID Control}

PID control is a combined control system of Proportional, integral and derivative controls. $\mathrm{P}$ control (proportional) has an influence on the system, including [11]-[13]:

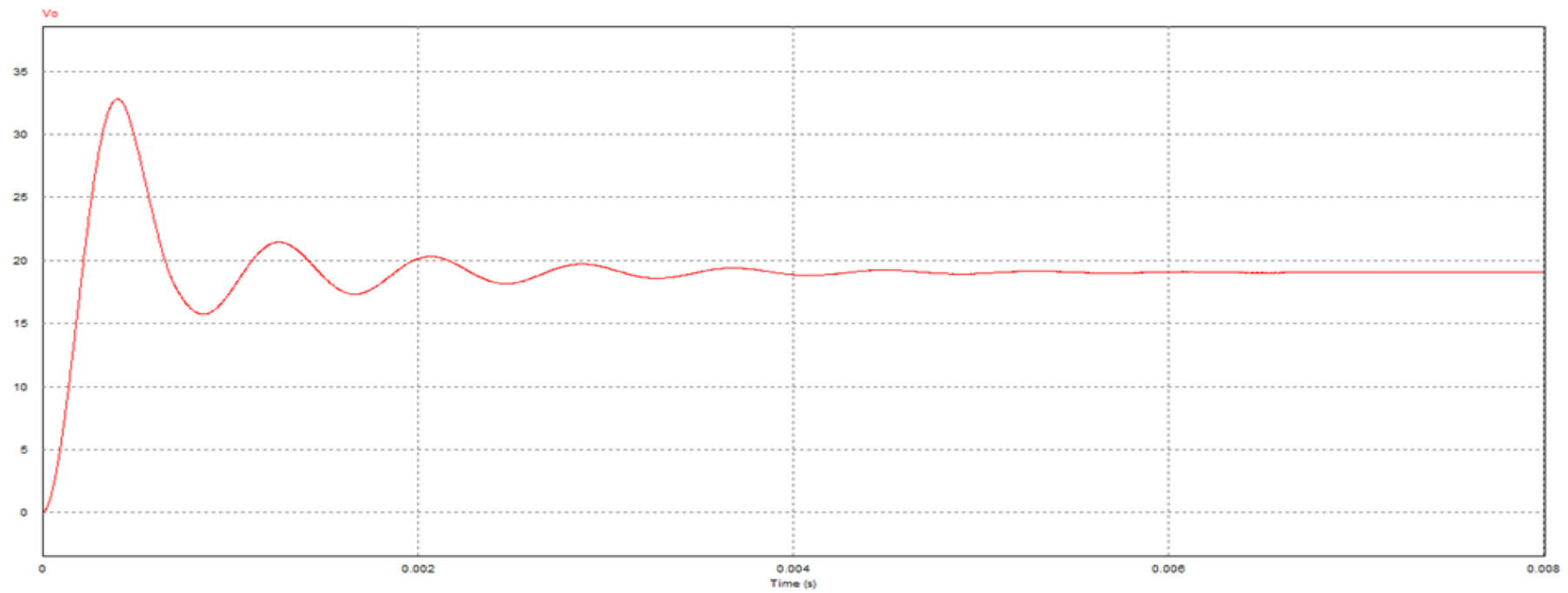

Figure 4. Buck converter connected with a Laptop without control

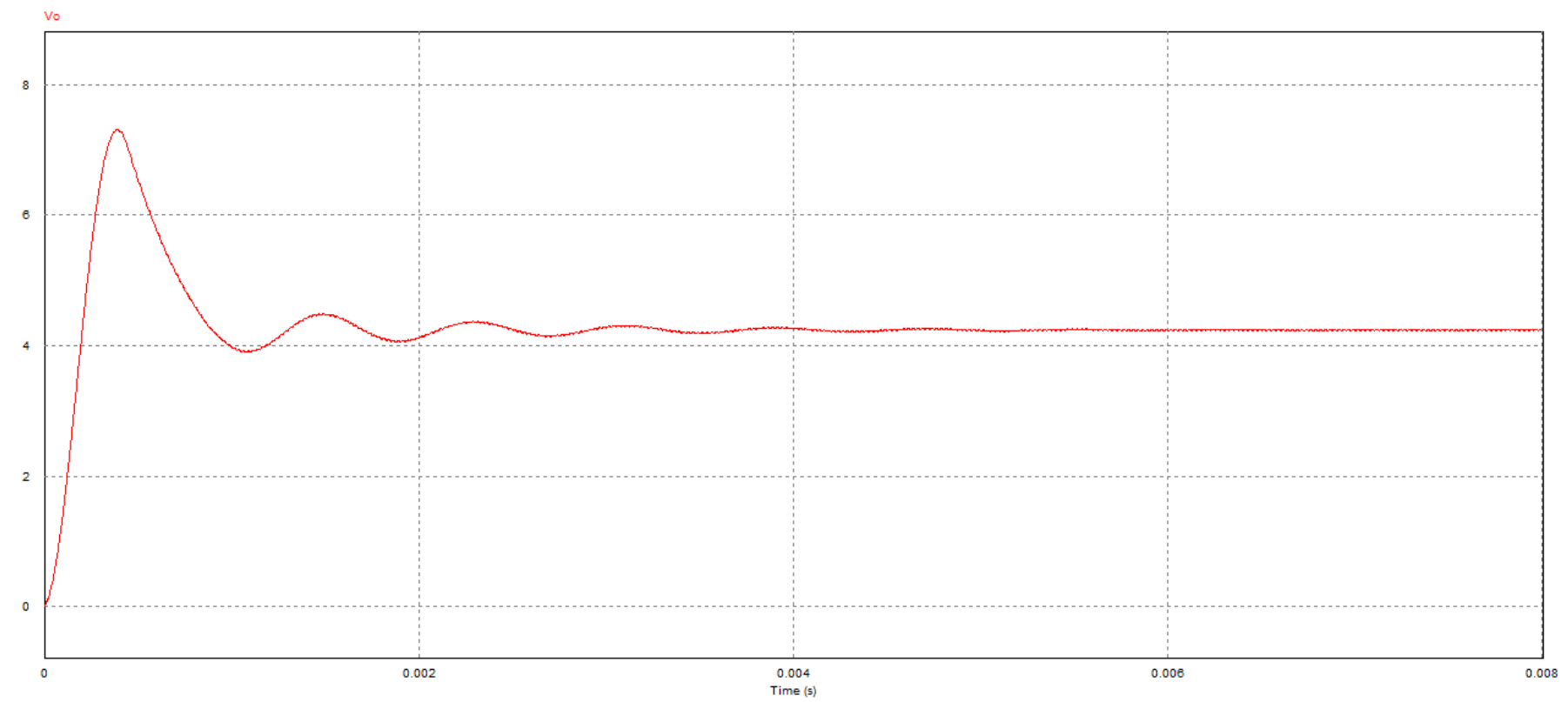

Figure 5. Buck converter connected with a Mobilephone without control

From the buck converter formula, to get an output voltage of 5 volts it takes a $20 \%$ duty cycle while to get an output voltage of 19 volt it takes an $80 \%$ duty cycle.
In the wave simulation results above there are overshoot and error steady state so that controls are needed. 
1. Add or reduce stability.

2. Can improve special rise time and setting time transient responses.

3. Reducing steady state errors by increasing the value of Kp which will make the system more unstable.

Control I (integral) has an influence on the system, including [14]-[15]:

1. Eliminate steady state error.

2. Slower response (compared to controller P).

3. Can cause instability because it adds to the system order.

The characteristics of D (differential) controls are as follows [16], [17]:

1. This controller cannot produce output if there are no changes to the input (in the form of an error signal).

2. If the error signal changes with time, then the output generated by the controller depends on the $\mathrm{Td}$ value and the error signal change rate.

3. The differential controller has a character to overtake, so this controller can produce a significant correction before the generator error becomes very large. So differential controllers can anticipate generating errors, provide corrective actions, and tend to improve system stability.

The PID control diagram block can be seen in Figure 6 below:

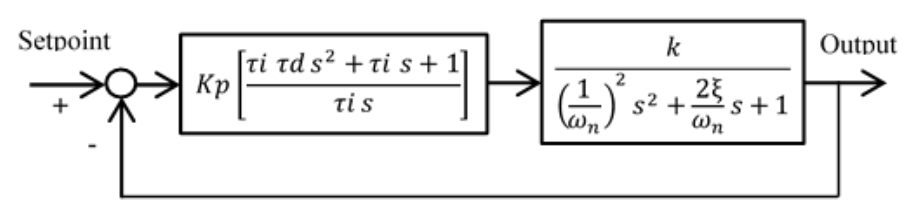

Figure 6. PID Controller

Design of PID control for Laptop:

$$
\begin{aligned}
& \mathrm{Kp}=(2.5657 \times 10)^{-2} \\
& \mathrm{Ki}=\mathrm{Kp} / \tau \mathrm{i}=998 \\
& \mathrm{Kd}=\mathrm{Kp} \tau \mathrm{d}=(16.035 \times 10)^{-6}
\end{aligned}
$$

Design of PID control for Mobile:

$$
\begin{aligned}
& \mathrm{Kp}=(3.045 \times 10)^{-2} \\
& \mathrm{Ki}=\mathrm{Kp} / \tau \mathrm{i}=1185 \\
& \mathrm{Kd}=\mathrm{Kp} \tau \mathrm{d}=(19.031 \times 10)^{-6}
\end{aligned}
$$

Note:

$$
\begin{aligned}
& \mathrm{Kp}=\text { Proportional gain } \\
& \mathrm{Ki}=\text { Integral gain } \\
& \mathrm{Kd}=\text { Derivative gain }
\end{aligned}
$$

The effects of each Proportional, Integral and Derivative controller on a closed loop system are summarized in Table 2 .

Table 2. PID Controller Response

\begin{tabular}{|c|c|c|c|c|}
\hline & $\begin{array}{c}\text { Rise } \\
\text { Time }\end{array}$ & Overshoot & Settling Time & $\begin{array}{c}\text { Steady } \\
\text { State Error }\end{array}$ \\
\hline $\mathrm{Kp}$ & Decrease & Increase & Small Change & Decrease \\
\hline $\mathrm{Ki}$ & Decrease & Increase & Increase & Eliminate \\
\hline $\mathrm{Kd}$ & Increase & Decrease & Decrease & No Chage \\
\hline
\end{tabular}

Each of the disadvantages and advantages of each controller P, I and D can cover each other by combining all three in parallel into a proportional controller plus a differential plus differential (PID controller). The control elements P, I and D respectively aim to [18]-[20]:

1. Speed up the reaction of a system reaching its set point

2. Eliminate offset

3. Produce large initial changes and reduce overshoot.

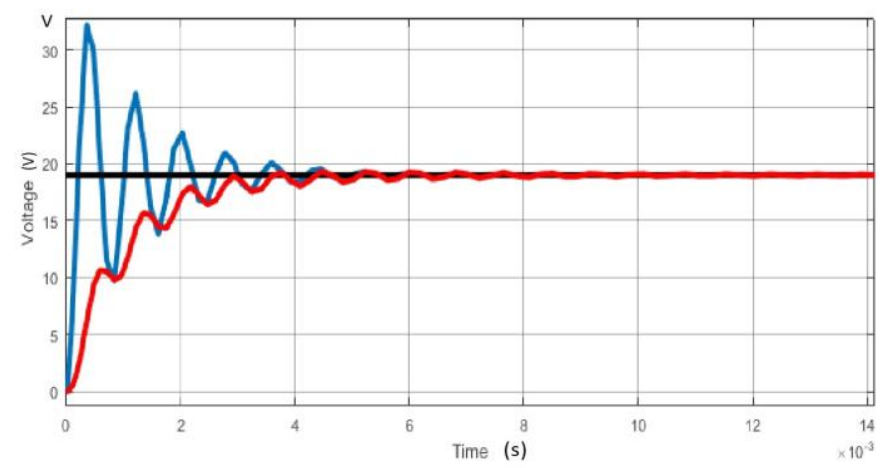

Figure 7. Comparison between Open Loop and Close Loop Wave for Laptop as Dc Load 


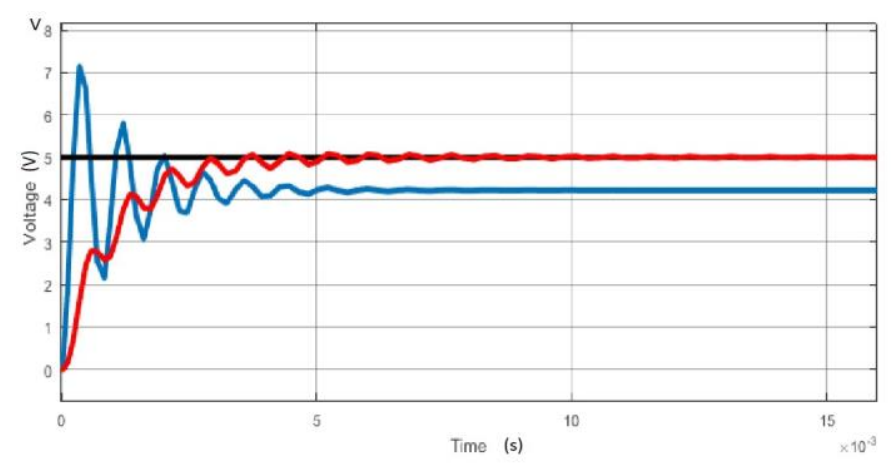

Figure 8. Comparison between Open Loop and Close Loop Wave for Mobile phone as Dc Load

Note:

$=$ Open loop

$=$ Close loop

$=$ Setting point

From Figure 7 and Figure 8 above it is known that the results of the voltage wave when controlled are better than before control. Blue line is an open loop voltage wave, a red line is a close loop voltage wave, whereas a black line is a voltage setting point value. Seen in close loop waves with PID control there is no overshoot and there is no steady state error on setting time $10 \mathrm{~ms}$.

\section{Results and Discussion}

The purpose of this simulation is to test the performance of the system produced by the PI controller.

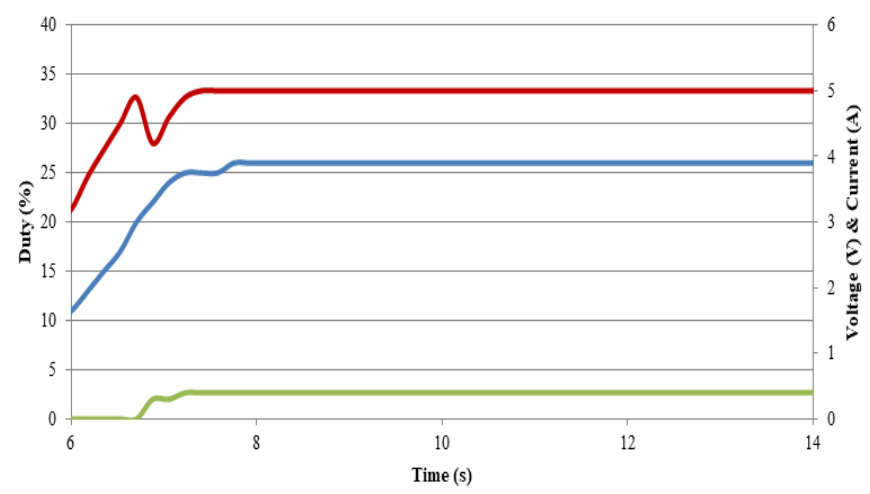

Figure 9. Adaptive Power Charge for Mobile phone

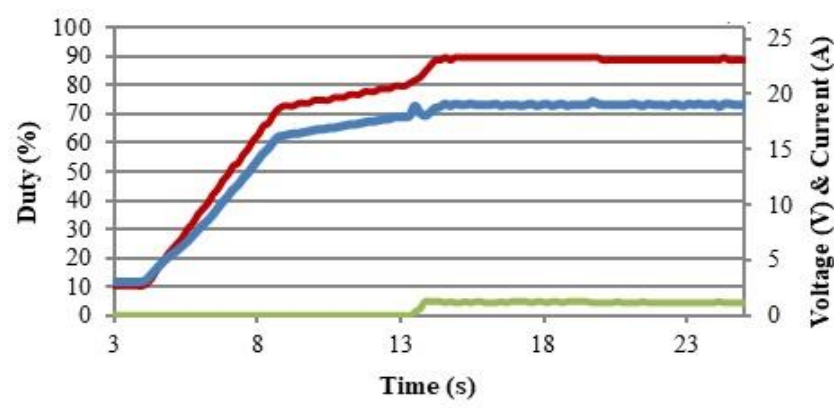

Figure 10. Adaptive Power Charge for Laptop

The experimental results above show charging using different types of dc loads. Figure 9 presents adaptive power charge for Mobile and Figure 10 presents adaptive power charge for Laptop. Through the graph can be seen before the system determines the setting point voltage, the system will tracking the duty cycle until there is a current. If there is a current flowing from the source to the load it indicates that the load has entered the charging process.

The characteristics of the graph above it can be seen that there is a voltage drop along with the increase in current. From there the system will select the load to determine the setting point voltage. After determining the setting point voltage, the unstable output voltage will be controlled using a PID control. From the experimental results it shows that the system is working properly because it uses Mobile, the system can provide a constant voltage of 5 volts. While using a Laptop, the system can provide a constant voltage of 19 volts for charging process.

\section{Conclusion}

Adaptive power charge simulation that is controlled using a PID controller has been presented.

1. Adaptive Power Charger is proven to be able to charge mobile phones and laptops very well.

2. Adaptive power charger can detect mobile phones and laptops with accuracy.

3. The battery charging current on mobile phones and laptops is stable as specified. 


\section{References}

[1] Ye Naung, Schagun Anatolii, Ye Htet Lin, "Speed Control of DC Motor by Using Neural Network Parameter Tuner for PI-Controller," IEEE Transactions on Power Electronics, p. 2152, 2019.

[2] Divya Asija, "Speed Control of Induction Motor Using Fuzzy-PI Controller," IEEE Transactions on Power Electronics, vol. 15: p. 460, 2010.

[3] Maycon Chimini Bosco, Jacqueline Jordan Guedes, Marcelo Favoretto Castoldi, Alessandro Goedtel, Emerson Ravazzi Pires da Silva, Luiz Fransisco Sanches Buzachero, "Estimation of Parameters and Tuning of a Speed PI of Permanent Magnet DC Motor Using Differential Evolution. IEEE Transactions on Power Electronics," 2017.

[4] CAO Fengwen, WANG Yiwang, "Study and Application of Fuzzy PID Control-Based for FFU Motor Speed Regulation Control System," IEEE International Electric Machines \& Drives Conference (IEMDC), p. 160. 2011.

[5] ZHANG Wei, YANG Maying, "Comparison of auto-tuning methods of PID Controllers based on models and closed-loop data," Proceedings of the 33rd Chinese Control Conference, p. 3661. 2014.

[6] WU Zhenlong, LI Donghai, WANG Lingmei,"Control of the Superheated Steam Temperature: A Comparison Study between PID and Fractional Order PID Controller," Proceedings of the 35th Chinese Control Conference, p. 10521. 2016.

[7] Fayez F. M. El-Sousy, "Design and Implementation of 2DOF I-PD Controller for Indirect Field Orientation Control Induction Machine Drive System," Electronics Research Institute, ERI, DOKKI, CAIRO, EGYPT, p. 1112, 2001.

[8] I. Jaziri, L. Charaabi and K. Jelassi, "A closed Loop DC Motor Control using low cost single-board microcontroller based on embedded Linux," 2016 International Conference on Electrical Sciences and Technologies in Maghreb (CISTEM), Marrakech, 2016, pp. 1-5, 2016.

[9] Greeshma Sarah John, Abhilash T Vijayan, “Anti-Windup PI Controller for Speed Control of Brushless DC Motor," International Conference on Power, Control, Signals and Instrumentation Engineering (ICPCSI), 2017, p. 1068.

[10] P. Kumar and V. Agarwal, "A study of conventional and fuzzy PI controller CSI fed induction motor," 2010 International Conference on Power, Control and Embedded Systems, Allahabad, 2010, pp. 1-5, doi: 10.1109/ICPCES.2010.5698619. 2010.
[11] D. Kumar, R. A. Gupta and N. Gupta, "Minimization of current ripple and overshoot in four switch three-phase inverter fed BLDC motor using tracking anti-windup PI controller," 2017 IEEE International Conference on Signal Processing, Informatics, Communication and Energy Systems (SPICES), Kollam, 2017, pp. 1-6, 2017.

[12] R. Maurya and M. Bhandari, "Design of Optimal PID[FOPID] Controller for Linear System," 2016 International Conference on MicroElectronics and Telecommunication Engineering (ICMETE), Ghaziabad, 2016, pp. 439-443, 2016.

[13] Zhenbo Pan, Fei Dong, Jiwen Zhao, Lijun Wang, Hui Wang, Yinyi Feng, "Combined Resonant Controller and Two-Degree-of-Freedom PID Controller for PMLSM Current Harmonics Suppression," IEEE Transactions on Industrial Electronics vol. 65 issue 9 pp. 7558-7568, 2018.

[14] Reza Ezuan Samin, Lee Ming Jie, Mohd. Anwar Zawai, "PID Implementation of Heating Tank in Mini Automation Plant Using Programmable Logic Controller (PLC)," International Conference on Electrical, Control and Computer Engineering, p. 515. 2011.

[15] Wang Xin, Li Ran, Wang Yanghua, Peng Yong, Qin Bin, "Self-tuning PID Controller with Variable Parameters Based on Particle Swarm Optimization," Third International Conference on Intelligent System Design and Engineering Application, p. 1264. 2013.

[16] S. Janarthanan, K.N.Thirukkuralkani, S.Vijayachitra, "Performance Analysis of Non-Integer Order PID Controller for Liquid Level Control of Conical Tank System," ICICES2014-S.A.Engineering College, Chennai, Tamil Nadu, India, 2014.

[17] Samart Singh, R. Mitra, "Comaparative Analysis of Robustness of Optimally Offline Tuned PID Controller and Fuzzy Supervised PID Controller," Porceedings of 2014 RAECS UIET Panjab University Chandigarh, 2014.

[18] Rohit Bhimte, Kalyani Bhole, Pritesh Shah,"Fractional order fuzzy PID Controller for a roatary servo system," Proceedings of the 2nd International Conference on Trends in Electronics and Informatics (ICOEI), p. 538. 2018.

[19] D K Sambariya, R. Prasad, D. Birla, "Design and Performance Analysis of PID based Controller for SMIB Power System using Firefly Algorithm," Proceeding of 2015 RAECS UIET Panjab University Chandigarh, 2015.

[20] K. Sundaravadivu, B.Arun, K. Saravanan, "Design of Fractional Order PID Controller for Liquid Level Control of Spherical Tank," IEEE International Conference on Control System, Computing and Engineering, p. 291. 2011. 